\title{
MANDIBULAR FIRST MOLAR WITH 5 CANALS- A RARE CASE REPORT
}

\author{
Snigdha Shubham ${ }^{1}$, Vanita Gautam ${ }^{2}$, Ourvind Jeet Singh ${ }^{3}$
}

\section{ABSTRACT:}

Success of endodontic treatment is solely dependent upon cleaning and shaping followed by three dimensional obturation. But this is not possible until and unless clinician doesn't have proper knowledge of anatomic variations and complexities. The purpose of this case report is to show the possibility of five root canals in first mandibular molar and imply the importance of scrutiny for identification and treatment of all the canals.

KEYWORDS: Anatomic variation; Endodontic treatment; Permanent mandibular first molar; Five canals

1. Post Graduate Resident, Department of Conservative and Endodontics, Universal College of Dental Surgery, Bhairahawa, Nepal

2. Associate Professor, Department of Conservative and Endodontics, Universal College of Dental Surgery, Bhairahawa, Nepal

3. Assistant Professor, Department of Conservative and Endodontics, Universal College of Dental Surgery, Bhairahawa, Nepal

\author{
For Correspondence \\ Dr. Snigdha Shubham \\ Post Graduate Resident \\ Department of Conservative and Endodontics, \\ Universal College of Dental Surgery, Bhairahawa, Nepal \\ E-mail: snigd123@yahoo.com
}




\section{INTRODUCTION}

Access opening, Cleaning and shaping and three dimensional obturation of canals are the three pillars for successful root canal treatment. Literature has provided different generalized principles and guidelines for proper access opening and localization of canals. But it cannot be denied with the fact that nature has so many surprising variations besides normalization. This is the reason why despite of adoption of all the suggested guidelines for endodontic treatment some treatment fails just because of the failure to localize extra canal.

The root canal morphology of permanent mandibular molar has racial variation and as well as intraracial variations too. In general population canal distribution in permanent mandibular first molar is two canals in the mesial root and one or two in the distal root ${ }^{1,2}$. Mandibular first molar root canal morphology is more variable and complex than its radiographic evaluation. ${ }^{3}$ Study done by Skidmore and Bjorndal stated that approximately one third of mandibular first molars studied had 4 root canals. Hence, radiographic examination and interpretation is the imminent part to identify unusual canal morphology associated with mandibular first molar teeth.

The groove between the mesiobuccal/mesiolingual and distobuccal/distolingual canals must always be troughed with a bur and /or ultrasonics and checked with files to search for mesial canal which is generally known as "middle mesial canal". The diameter of those third middle canals is smaller than that of the other two. ${ }^{5}$ The probability of a mandibular first molar having a fifth canal is $115 \%$.

Hence when a preoperative radiograph reveals an atypical tooth shape and an unusual contour, further radiographs at different angles, if necessary, and cone-beam computed tomography scans should be taken to confirm any unusual anatomical features.

This case report describes the diagnosis and successful management of a case of mandibular first molar with this unusual morphological variation of three mesial canals.

\section{CASE REPORT}

An 18 years old female patient presented to the Department of Conservative and endodontics, Universal College of Dental Surgery, Bhairahawa, Nepal with the chief complaint of pain in right side of the lower jaw. The pain was moderate to severe in intensity, throbbing in nature, continuous with episodes of exacerbation at night. Pulp test and percussion test was performed. Radiograph revealed deep caries in coronal portion approaching pulp and the apical portion of the roots revealed radiolucency with indistinct margin. Diagnosis of symptomatic apical periodontitis was made and advised for endodontic treatment.
The pre-operative radiographic evaluation did not revealed any variation in the canal anatomy as shown in figure 1 .

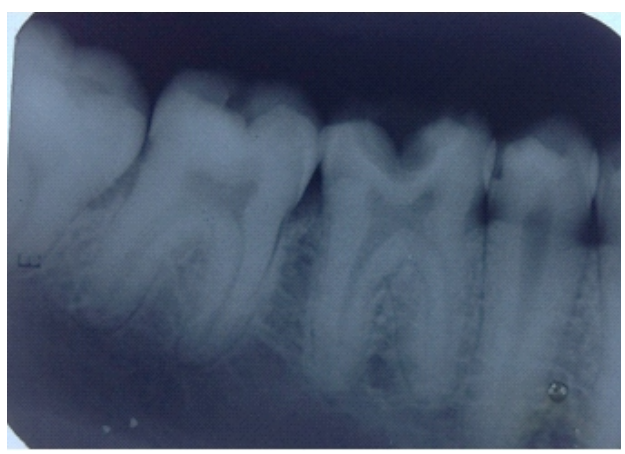

Figure 1: Pre-operative radiograph

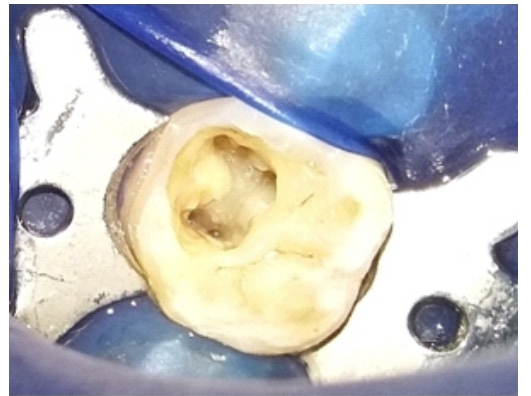

Figure 2: Access opening showing three mesial orifices and

The tooth was anesthetized with $1.8 \mathrm{ml}$ of $2 \%$ lidocaine HCL with 1: 200000 epinephrine (LOX 2\%,India) followed by rubber dam isolation. Endodontic access cavity was performed with endo access bur (Dentsply Maillefer, Ballaigues, Switzerland). Pulpal floor was examined with DG 16 endodontic explorer which revealed three canals in the mesial root in between the mesiobuccal and mesiolingual groove and two canals in the distal root (Shown in fig 2). \# 10 $\mathrm{K}$ file (Dentsply) was inserted into all the five canals for apical patency. Coronal flaring for straight line access was done with protaper SX file (Dentsply, Malliefer, Ballalgues, Switzerland ). Working length was determined by Propex III apex locater (Dentsply,Switzerland) and later confirmed by IOPAR in different angulation. The IOPAR revealed five canals as shown in fig 3 ).

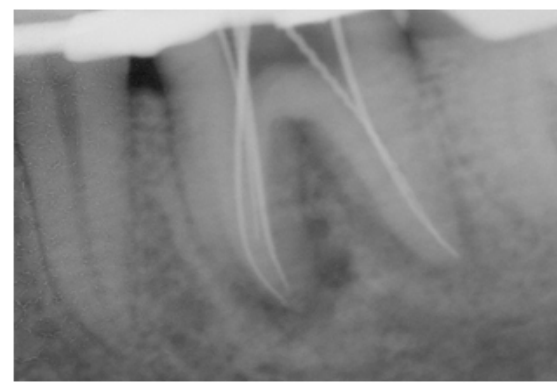

Figure 3: Working length IOPAR 


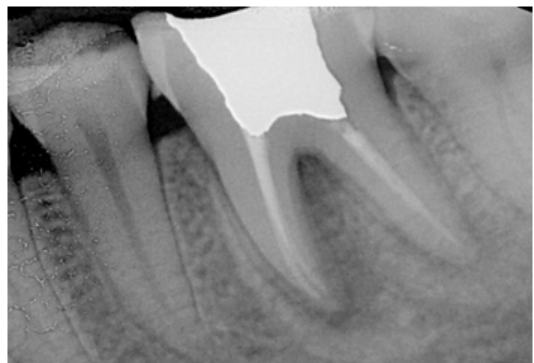

Figure 4: Immediate Post obturation radiograph

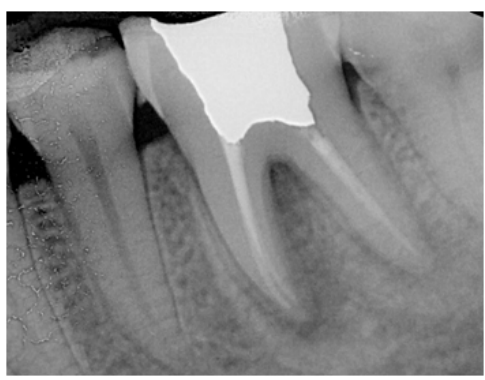

Figure 5: After 3 months

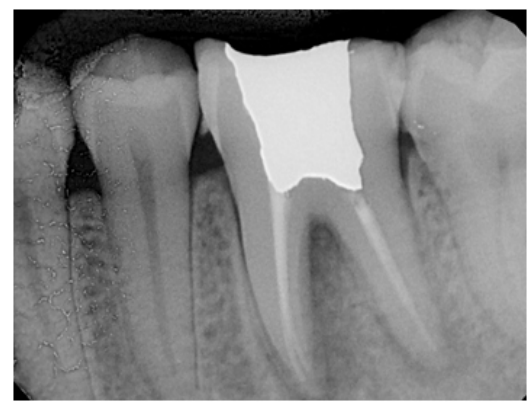

Figure 6: After 6 months

All the canals were cleaned and shaped with crown down technique using Protaper hand files (Dentsply, Malliefer, Ballalgues, Switzerland). Irrigation was done with $5 \% \mathrm{NaOCl}$ (Dentpro, India) , 2\% chlorhexidine (Consepsis V, Ultradent, India) and normal saline. Calcium hydroxide (Pyrax, India) dressing was placed for one week. At second appointment patient was asymptomatic hence obturation was done with single cone technique using protaper gutta-percha(Dentsply, Malliefer, Ballalgues, Switzerland) as shown in fig 4.Patient was asymptomatic at six month follow up and hence not reported with any complain till now. Periapical healing was evident in IOPAR at 3 months and 6 months follow up as shown in fig 5 and 6.

\section{DISCUSSION}

Common mistake usually done by the clinicians is that they predetermine the number of roots and root canals. But the literature has ample of studies about the anatomy of root canals such as Vande Voorde et al. ${ }^{8}$, Badanelli and MartinezBerna ${ }^{9}$ and Fabra-Campos ${ }^{10}$ which reinforced the importance of an accurate clinical evaluation of a possible fourth or fifth root canal in permanent mandibular molar to ensure success of endodontic treatment. Similarly study done by MartinezBerna and Badanelli ${ }^{11}$ also focused on the importance of investigating the existence of a fourth and even a fifth root canal.

Hence taking into consideration of various studies that have shown that deviation from the normal is very frequent than earlier observed. Use higher magnification and advanced diagnostic aids like CBCT should be indicated for improved clinical chances of diagnosing, locating, and treating extra canals.

Pomeranz et al. in their study of 100 molars (61 first and 39 second molars) reported 12 cases of middle mesial canals. They classified middle mesial canal into three categories: (1) fin, when at any stage of debridement the instrument could pass freely between mesiobuccal or mesiolingual canal and the middle mesial canal, (2) confluent, when the prepared canal originated as a separate orifice but apically joined the mesiobuccal or mesiolingual canal, and (3) independent, when the prepared canal originated as a separate orifice and terminated as a separate foramen. ${ }^{12}$

Clinical evaluations have shown a small but significant number of mandibular molars with five canals.The region between the mesiolingual and mesiobuccal canals should be carefully examined in case of the possible occurrence of a fifth canal.

\section{CONCLUSION}

The present case report basically describes the importance of "A mindful practice". A mandibular first molar with five canals, three in the mesial and two in the distal canal was successfully detected and treated. It is mandatory that the clinician should possess a thorough knowledge of not only the normal anatomy of the root canal system, but also aberrations. Thus, multiple angulated radiograph and close clinical inspection of the chamber floor at higher magnification is essential while treating teeth that have a high incidence of extra canals. 


\section{REFERENCES}

1. Gulabivala K, Opsanon A, Ng YL, Alavi A. Root and canal morphology of Thai mandibular molars.Int Endod $J$ 2002;35:56.

http://dx.doi.org/10.1046/j.1365-2591.2002.00452.x PMid:11853239

2. F. J. Vertucci, "Root canal anatomy of the human permanent teeth," Oral Surgery Oral Medicine and Oral Pathology 1984;58: 58999 .

http://dx.doi.org/10.1016/0030-4220(84)90085-9

3. Vertucci FJ. Root canal anatomy of the human permanent teeth. Oral Surg Oral Med Oral Pathol. 1984; 58:589-99. http://dx.doi.org/10.1016/0030-4220(84)90085-9

4. Skidmore AE, Bjorndal AM. Root canal morphology of the human mandibular first molar. Oral Surg Oral Med Oral Pathol. 1971; 32:778-84

http://dx.doi.org/10.1016/0030-4220(71)90304-5

5. S Poorni, RA Kumar, and R Indira, Canal complexity of a mandibular first molar, J Conserv Dent. 2009 Jan-Mar; 12(1): 3740

http://dx.doi.org/10.4103/0972-0707.53341

PMid:20379439 PMCid:PMC2848812

6. H. Fabra-Campos, "Unusual root anatomy of mandibular first molars, "Journal of Endodontics 1985;11(12):56872.

http://dx.doi.org/10.1016/S0099-2399(85)80204-1
7. F. de Almeida-Gomes, C. Maniglia-Ferreira, B. Carvalho-Susa, and R. A. dos Santos, "Six root canals in maxillary first molar,"Oral Surgery,OralMedicine, Oral Pathology, Oral Radiology, and Endodontology 2009; 108:e157e159. http://dx.doi.org/10.1016/j.tripleo.2009.04.032 PMid:19716486

8. Vande Voorde HE, Odendahl D, Davis J. Molar 4th canals: frequent cause of endodontic failure. III. Dent J 1975; 44: 77986

9. Badanelli P, Martinez-Berna A. Obturacion de un molar inferior con cinco conductos. In: Lasala A, ed. Endodoncia.Barcelona: Salvat S. A.; 1979.p. 407

10. Fabra-Campos CH. Unusual root anatomy of mandibular first molars. JEndod 1985; 11: 56872

http://dx.doi.org/10.1016/S0099-2399(85)80204-1

11. Fernando Branco Barletta,Sidney Ricardo Dotto, Magda de Sousa Reis, Ronise Ferreira, and Rosana Maria Coelho Travassos, Mandibular molar with five root canals, Aust Endod J 2007 .

12. H. H. Pomeranz, D. L. Eidelman, and M. G. Goldberg, "Treatment considerations of the middle mesial canal of mandibular first and second molars, "Journal of Endodontics, 1981;7(12): 5658 .

http://dx.doi.org/10.1016/S0099-2399(81)80216-6 